\title{
Ärztliche Totalamnesie nach nur zehn Jahren in der Praxis?
}

— Als Hausärztin biete ich auch Psychotherapie an. Dabei ist oft als erstes zu klären, ob eine solche Behandlung überhaupt angezeigt ist. So auch neulich, als eine Patientin zu mir kam, die auf Therapieplatzsuche war. Bei ihr war ihr Bruder, der mich anlächelte und sich verhielt, als würde er mich gut kennen. Leider konnte ich mich gar nicht an ihn erinnern, wobei man nach über zehn Jahren Niederlassung auch nicht mehr den Anspruch hat, jeden Patienten wiederzuerkennen. Ich lächelte nur freundlich zurück und sprach erst einmal mit der Schwester.

Sie schilderte ihre seit längerem bestehenden Probleme. Gerade stecke sie in einer Krise, und nun habe sie sich endlich dazu durchringen können, eine Therapie zu beginnen. Ihr Bruder habe mich wärmstens empfohlen. Wir vereinbarten einen Probetermin, und die Patientin verabschiedete sich. Der Bruder hingegen wollte noch etwas mit mir bereden.

\section{Ein guter Eindruck, der lange vorhält}

Er eröffnete mir, dass er vor 15 Jahren mal eine Gruppentherapie bei mir gemacht habe, welche sehr erhellend gewesen sei. Deshalb sei er froh, dass ich seine Schwester nun behandeln werde, weil seine Kräfte langsam an ihre Grenzen stießen.

Ich hatte nicht nach seinem Namen fragen mögen, um nicht durch meine "Vergesslichkeit" die potenzielle Therapiebeziehung zur Schwester zu gefährden. Nun beriet ich ihn aber zu weiteren Möglichkeiten, die Verantwortung für seine Schwester an entsprechende Stellen abzugeben. Es ging also um seine eigenen Anliegen, und ich konnte guten Gewissens seine Versichertenkarte fordern. Innerlich war ich doch etwas beunruhigt wegen meiner ihn betreffenden „kompletten Amnesie“. Man kann doch einen Gruppentherapiepatienten, den man ca. ein Jahr lang wöchentlich gesehen hat, nicht völlig vergessen!

Als ich dann aber seine Akte zur Dokumentation bekam, konnte ich mich entspannen. Der Mann hatte tatsächlich vor genau 15 Jahren eine Gruppentherapie in unserer Praxis gemacht - nur das ich damals noch gar nicht hier tätig war! Der Erinnerungsfehler lag also nicht bei mir.

\section{Hier steht eine Anzeige.}

\author{
Springer
}

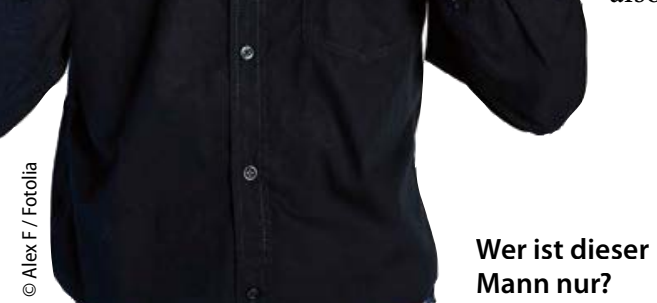

Dr. Andrea Linsel, Lüneburg 